\title{
História, historiografia e pesquisa histórica
}

\author{
Entrevista com Maria Fernanda B. Bicalho
}

\begin{abstract}
Maria Fernanda Baptista Bicalho pertence a uma geração de historiadores que deu um novo "tom" à historiografia brasileira. Tal cenário encontraria seus desafios diante dos novos questionamentos feitos à historiografia sobre o Brasil colonial, mas também impulsionou e enriqueceu a pesquisa no Brasil. Professora e atual coordenadora do Programa de Pós-Graduação em História da Universidade Federal Fluminense, Maria Fernanda Bicalho é a nossa convidada especial para falar sobre o atual estágio das pesquisas sobre o Brasil colonial.
\end{abstract}

Outros Tempos - Vamos iniciar nossa conversa apresentando sua formação acadêmica.

Fiz graduação em História na PUC-RJ e mestrado em Antropologia Social no Museu Nacional, UFRJ, numa época - década de 1980 - em que os estudos de Clifford Geertz e Robert Darnton, traduzidos no Brasil, eram testemunhos da crescente interlocução entre as duas disciplinas e do surgimento, entre nós, da História Cultural. Comecei a dar aulas muito cedo. Em 1983 já era professora da PUC. Entre 1988 e 1992, depois de ter defendido minha dissertação de mestrado sobre a imprensa feminina no Rio de Janeiro entre a segunda metade do século XIX e os primeiros anos do século XX, além de professora em várias universidades e faculdades particulares, envolvi-me em pesquisas sobre mulheres (gênero) e cinema. Em 1990 entrei na UFF como professora substituta e em fins de 1991 fiz concurso para ser efetivada. Só então decidi fazer o doutorado e, ao escolher o curso de História Social na USP, e a professora Laura de Mello e Souza, que aceitou me orientar, voltei-me para os estudos sobre História Moderna e do Brasil colonial, uma vez que, até então, minha atividade docente era muito mais voltada para a História do Brasil imperial e republicano, embora também ministrasse a disciplina "Brasil Colônia".

OT -Você participou da organização de uma obra -"O Antigo Regime dos trópicos: a dinâmica imperial portuguesa (séculos XVI - XVIII)" - editada pela Civilização brasileira, em 2001 que instigou um profícuo debate sobre as interpretações do Brasil colonial. Como você avalia, hoje, os impactos dessa obra na historiografia brasileira?

Quando, em inícios de 2000, João Fragoso, Maria de Fátima Silva Gouvêa e eu nos reunimos para organizar $O$ Antigo Regime nos Trópicos, não tínhamos a dimensão da importância que esta obra assumiria nos estudos de História sobre o período colonial no Brasil, nem podíamos imaginar a grande repercussão do livro, cuja segunda edição encontra-se já esgotada. Hoje é evidente que o impacto dessa obra na historiografia brasileira foi enorme. O que nos moveu a organizar o livro e a convidar os autores que dele participaram foi uma insatisfação com os modelos explicativos então dominantes 
sobre a época colonial: análises macroestruturais que forjaram a imagem da colônia como um todo homogêneo, sem que fossem consideradas conjunturas e singularidades regionais, sociais, econômicas e inclusive cronológicas dos diferentes territórios que a constituíram ao longo de mais de três séculos. Teses como as do sentido da colonização, desenvolvida por Caio Prado Júnior em 1942, e do antigo sistema colonial, formulada por Fernando Novais na década de 1970, fundamentadas na noção de um pacto marcado pelo exclusivo comercial e pela exploração da metrópole sobre a colônia, se praticamente negavam aos atores engendrados na dinâmica da colonização possibilidades múltiplas de escolha e de negociação de suas estratégias individuais e sociais, tornando-os mais objetos do que sujeitos de seus destinos históricos, minimizavam, igualmente, a rica diversidade regional e temporal dos domínios americanos da monarquia portuguesa. Em obras como A Formação do Brasil Contemporâneo, apesar de todos os seus méritos e de seu caráter inovador na época em que foi publicada, a idéia da constituição da nação e do nacional serviu de base para se pensar retroativamente a colônia. No que diz respeito ao poder, à política e à administração, muitos historiadores insistiam na distância entre o país formal, existente nas normas jurídicas portuguesas, e o país real da colonia, onde as leis eram freqüentemente não ou mal aplicadas. Estudos considerados clássicos na historiografia brasileira partiam de uma dualidade constituída por duas "realidades" distintas e por vezes contraditórias: a da metrópole e a da colônia. Embora estes modelos explicativos fossem hegemônicos até a década de 1990, não eram certamente os únicos. No campo da história econômica e social, podemos citar, entre outros, os trabalhos de José Roberto do Amaral Lapa, João Fragoso e Manolo Florentino; e, no que diz respeito às práticas políticas e administrativas não só na América, mas no conjunto do império português, as obras de C. R. Boxer, John Russell-Wood e Stuart Schwartz foram pioneiras no que diz respeito a um novo ponto de vista.

De forma inovadora e coletiva, os capítulos do livro $O$ Antigo Regime nos Trópicos apresentaram outra perspectiva historiográfica. Propunham-se a desenvolver uma nova abordagem dos domínios portugueses na América, procurando percebê-los como parte constitutiva do império português. Propunham-se, ainda, a compreender a sociedade escravista como resultado de dinâmicas económicas, políticas, ideológicas e culturais de Antigo Regime. O capítulo escrito por Hebe Mattos em O Antigo Regime nos Trópicos é tão original, quanto precursor nesse sentido. As principais questões que nos motivaram ao organizar o livro consistiam em desfazer uma interpretação fundada na irredutível dualidade econômica, social e cultural entre a metrópole e a colônia; em demonstrar que, ao lado dos - e, às vezes, simultaneamente aos - conflitos entre colonos e coroa, inúmeras foram as negociações que fundaram e conferiram estabilidade ao império; em tecer um novo ponto de vista e um novo arcabouço teórico e conceitual que, ao partir de dinâmicas particulares ao Antigo Regime, pudesse explicitar práticas e instituições presentes na sociedade colonial. Ou ainda, desfazer uma interpretação fundada na dualidade entre a metrópole e a colônia, entre o formal e o real, o método e o caos, e propor uma nova chave interpretativa que, ao dar conta da lógica do poder, das práticas políticas e da administração colonial, não redundasse numa visão negativa, que insistisse tão somente na ineficiência, na não adaptação, no desgoverno e no caos.

OT - Quais os fundamentos desse novo olhar historiográfico?

Há muito a historiografia, principalmente a anglo-saxônica, utiliza, na análise das relações ultramarinas e coloniais, um conceito só muito recentemente incorporado à produção acadêmica brasileira: o de império português. Desde a década de 1960, C. R. 
Boxer discute a construção da soberania portuguesa em áreas tão distintas, quanto distantes, conjugando a comunicação política entre poderes locais e o centro da monarquia, redes comerciais, incursões missionárias, campanhas militares e administração imperial. Esta abordagem fez escola, distinguindo alguns de seus discípulos, como Russell-Wood, cujo livro, Um Mundo em Movimento. Os Portugueses na África, Ásia e América, é uma contribuição fundamental à análise da rica complexidade do império português. Para nós, na época do lançamento de $O$ Antigo Regime nos Trópicos, e ainda hoje, passados mais de dez anos, o diálogo com a produção historiográfica européia, principalmente ibérica, sobre a cultura política das monarquias de Antigo Regime apontava caminhos que vêm sendo trilhados nas últimas décadas pela produção acadêmica que rompe, nos dois lados do Atlântico, com a visão estadualista e dualista do processo de colonização dos tempos modernos. Creio que posso afirmar - e não falo só por mim, mas por toda uma nova geração de historiadores - que o contato com a obra de António Manuel Hespanha foi um fator responsável pela difusão na comunidade acadêmica brasileira de conceitos e perspectivas já então correntes na historiografia ibérica, apresentando-nos as obras de autores como Bartolomé Clavero e Pablo Fernández Albaladejo, entre outros, incentivando jovens pesquisadores brasileiros a reverem categorias como as de Estado, centralização, poder absoluto ou absolutista, assim como sua eficácia na análise das monarquias européias da época moderna e de seus domínios ultramarino. E gostaria de voltar a ressaltar aqui o mérito e a abrangência desta influência no sentido da ruptura - ou seja, do estabelecimento de um novo paradigma historiográfico - por meio da operacionalização de novas categorias e conceitos para a interpretação de antigos documentos, no intuito de compreender a matriz ideológica - católica e corporativa - da monarquia portuguesa, e, sobretudo, de refletir sobre a arquitetura, as configurações, as dinâmicas, as práticas e representações do império português. Hoje partimos da idéia de que o poder político ilimitado, característico de Estados centralizados, não existiu neste tipo de império. Mas sim, justaposição institucional, pluralidade de modelos jurídicos, limitações constitucionais do poder régio e o consequiente caráter mutuamente negociado de vínculos políticos. Enfim, assim como na Europa, também no ultramar coexistia a estrutura plural e complexa de diferentes comunidades políticas.

OT - A produção historiográfica brasileira sobre o período colonial nunca foi tão "vibrante" e intensa. A que você atribui esse vigor?

Não só novas perspectivas e conceitos, mas também novos temas tornaram-se objetos privilegiados de pesquisa. E, o mais importante, uma volta aos arquivos, seguida de uma investigação acurada em diferentes fundos documentais, tanto no Brasil, quanto em Portugal. Maior atenção vem sendo dada, em dissertações de mestrado e teses de doutorado, ao estudo dos poderes locais, nomeadamente das câmaras, das ordenanças e forças auxiliares. Em relação aos ofícios e oficiais de justiça, é impressionante a quantidade e a qualidade de novos trabalhos sobre o papel e a atuação de juízes e ouvidores, seja nos domínios da coroa, seja em terras dos donatários, assim como de seus conflitos e negociações, tanto com outros funcionários régios, como com as elites e populações locais. Os funcionários da justiça régia ganharam, enfim, um lugar privilegiado no seio da historiografia brasileira, tema que, desde o estudo clássico de Stuart Schwartz sobre o Tribunal da Relação da Bahia, não obteve, até muito pouco tempo atrás, o protagonismo ora alcançado. E, ainda, estudos voltados para os ofícios menores ou inferiores, os meirinhos, os escrivães, os secretários, como nos recentes trabalhos de Caio Boschi, Pedro Puntoni e Maria de Fátima Gouvêa, entre tantos outros. 
Também as análises sobre as elites na colônia, em toda sua multiplicidade: elites econômicas, mercantis, administrativas, senhoriais, indígenas, são tributárias desta renovação historiográfica, vibrante e intensa. É preciso ressaltar que, igualmente no que diz respeito à escravidão - uma vez que, como escreveu Sílvia Lara, a presença maciça de escravos diferenciava a experiência colonial da metropolitana, redimensionando e dando novo significado às práticas hierárquicas que ordenavam as sociedades no Antigo Regime - novas pesquisas superaram antigas dicotomias fruto de análises macroestruturais, voltando-se para as especificidades das relações entre senhores e escravos, também elas marcadas, para além da violência e da dominação, por múltiplas estratégias de negociação. Cada vez um maior número de historiadores, dos mais experientes aos mais jovens, vem se debruçando sobre o significado da presença de africanos e afrodescendentes num contexto no qual o racismo - pelo menos de acordo com a definição instituída no século XIX - não havia ainda se consolidado. Nos últimos anos surgiu um grupo de pesquisadores especialistas na história da escravidão africana nos séculos XVII e XVIII, assim como na história das sociedades africanas. Este movimento tem sido reforçado por pesquisas sobre temas correlatos, como o do cativeiro indígena, das sociedades e culturas ameríndias, assim como de suas estratégias de resistência e adaptação aos códigos e hierarquias impostas pela cultura política do colonizador. Conectam-se, assim, por meio de pesquisas minuciosas e da utilização de uma documentação variada, novos objetos e renovação historiográfica. A recente produção de historiadores, como João Fragoso, Roquinaldo Ferreira, Hebe Mattos, além de muitos outros, atesta o desenvolvimento e o amadurecimento desta profícua interlocução entre análises do Antigo Regime e da escravidão colonial e Atlântica.

OT - Até que ponto a Nova História produzida no Brasil tem ultrapassado os muros da academia?

A primeira coisa que me vem à mente é o campo aberto pela Revista de História da Biblioteca Nacional durante todos estes anos. Creio que ela foi um veículo importante de divulgação, para um público muito mais amplo, de pesquisas de ponta e análises inovadoras. A publicação de teses e dissertações nos sites dos Programas de PósGraduação nos quais foram defendidas também desempenha um papel de multiplicação do conhecimento. No entanto, creio que sua consulta é restrita ao mundo acadêmico. Por outro lado, os livros didáticos, principalmente aqueles submetidos à avaliação do MEC, por meio do Programa Nacional do Livro Didático, no qual historiadores e professores de História de diferentes níveis e instituições de todo o Brasil são os avaliadores, têm demonstrado a incorporação e a propagação de novas abordagens. Porém, mesmo que editados, poucos são os trabalhos produzidos em nossas Universidades que suscitam o interesse de um público não "especialista". Mas talvez não seja esse - o de ultrapassar os muros da academia - o objetivo ou o "destino" da produção acadêmica, nem na área de História, nem em qualquer outra área, seja das ciências humanas, seja das tecnológicas ou da saúde. A não ser quando nós, historiadores, nos propomos a escrever livros para o grande público. Digo, "nós historiadores", pois a meu ver os livros escritos por outros especialistas, como jornalistas, em geral, embora possam abordar temas históricos, não possuem o rigor teórico e metodológico da nossa disciplina.

OT - O que priorizar a respeito da História do Brasil colonial aos alunos do ensino básico? 
Não sou, propriamente, uma especialista em "ensino básico", ou mesmo no campo do Ensino de História, área que vem se desenvolvendo de forma magistral e tem produzido excelentes reflexões e trabalhos, além de conquistar um espaço absolutamente merecido em fóruns, congressos e seminários regionais e nacionais, como os da ANPUH, por exemplo. Como coordenadora atual do PPGH-UFF, tenho participado dos Fóruns de Coordenadores de Programas de Pós-Graduação da ANPUH e de reuniões com a CAPES, nas quais tem se discutido a importância da criação de cursos de Mestrado Profissional voltados para os professores de História atuantes no ensino fundamental e médio, política que conta com todo o meu apoio e adesão. Nunca dei aulas para alunos do ensino fundamental e médio, porém já tive contato com professores da rede pública e particular por ter atuado, durante muitos anos, no curso de Pós-Graduação Lato-Sensu de História do Brasil, organizado pelo Departamento de História da UFF e oferecido a um público diverso, porém constituído em boa medida por professores do ensino básico. Por outro lado, desde a década de 1990, integro, na UFF, o Núcleo de Estudos de História Cultural (NUPEHC), que, constituído por professores de diferentes áreas e disciplinas - como História do Brasil, da América, Moderna e Contemporânea - elegeu, durante as duas últimas décadas, temas como Ensino de História, Culturas Políticas e Historiografia como um ponto de reflexão comum e de produção coletiva. Desde o ano 2000 temos publicados vários livros sobre o assunto, o que fez com que, a partir da interlocução com meus colegas, alguns deles especialistas no tema, eu aprendesse muito e tentasse, sobretudo, refletir sobre o ensino da história colonial a alunos que não os da universidade, onde atuo. Por outro lado ainda, fiz parte, nos últimos anos, da equipe de pareceristas do Programa Nacional do Livro Didático, do MEC, tanto voltado para o ensino fundamental, quanto para o ensino médio. Devo confessar que avaliar os livros didáticos inscritos neste Programa foi uma experiência incrível e desafiadora. Tanto devido à minha inexperiência como professora de "escola", quanto pela longa experiência em arquivos e em sala de aula na universidade. Daí o meu contato com os livros didáticos e com um pouco da "realidade" do "ensino básico". Bem sei que uma coisa são os livros, e outra é o dia a dia na sala de aula, em contato com os alunos. O que posso dizer, acerca da pergunta que me foi feita, é que não só em relação à História do Brasil Colonial, mas no que diz respeito à História, em qualquer temporalidade, e qualquer espacialidade - pressupostos que marcam a nossa disciplina - o importante é desconfiar dos argumentos peremptórios, das visões maniqueístas ou dualistas, que não permitam a reflexão dos próprios alunos. O importante é percebermos, e ensinarmos, que diferentes momentos históricos implicam em questionamentos distintos e em perspectivas historiográficas específicas. O historiador é um sujeito de seu tempo e as questões que coloca ao seu objeto de estudo, e às fontes que escolhe analisar, não estão dissociadas da conjuntura política, social, econômica e cultural na qual nos inserimos. E isso não vale apenas para o ensino da História do Brasil Colonial, e sim para o ensino da História como um todo.

OT - Diante da necessidade de o historiador compreender as conexões e estratégias das dominações ultramarinas ainda cabe se falar em historiografia regional e historiografia brasileira?

Não sei se o termo seria "historiografia regional", uma vez que em pleno século XXI, os historiadores não estão mais imunes a influências "externas" de todo o tipo, por meio dos mais diversos veículos de comunicação e divulgação. Mas é importante valorizar estudos regionais atentos às singularidades de uma determinada localidade, 
território ou região. Estes estudos continuam vivos e dinâmicos e são, a meu ver, de suma importância para que continuemos a tratar a História como um "inventário das diferenças", para citar Paul Veyne. No entanto, eles apresentam hoje - pelo menos os que são realizados nas universidades, instituições de pesquisa e Programas de PósGraduação em todo o Brasil - outra grande e importante diferença em relação aos que eram produzidos a partir de fins do século XIX e inícios do XX, principalmente nos Institutos Históricos e Geográficos estaduais, cujo objetivo maior era pensar os fundamentos de uma "identidade regional" a partir da trajetória dos "grandes homens" e de seus feitos nos locais em que nasceram e atuaram. Hoje em dia, os estudos que privilegiam temas, objetos e documentos inscritos numa determinada região dialogam não apenas com outros estudos sobre os mesmos temas e objetos em outras regiões do Brasil, mas alguns vão além, tecendo comparações e ressaltando singularidades locais ou regionais com base em ampla historiografia, não apenas relativa ao Brasil ou à América portuguesa, mas cotejando exemplos da América hispânica e/ou britânica, de outros territórios ultramarinos na África e no Oriente, e ainda das monarquias européias. Parafraseando Sanjay Subrahmanyam, seguido por Serge Gruzinsky, hoje em dia os estudos locais ou regionais, quando despidos dos vários "centrismos" (eurocentrismo, etnocentrismo, etc.) não podem sobreviver se não conectarem histórias e historiografias.

OT - Como você situa a produção historiográfica no Brasil atualmente?

Atualmente, a produção historiográfica no Brasil, especificamente no que diz respeito aos estudos de História Moderna, nos quais se incluem dos de Brasil colonial, situa-se e conecta-se com o que há de mais inovador em termos da historiografia internacional. Hoje em dia é mais perceptível e menos contestável o quadro atomístico da expansão portuguesa. Recentes estudos vêm incorporando a idéia da inexistência de um projeto colonial a priori, de um modelo ou estratégia geral abrangendo todo o império, pelo menos até aos meados do século XVIII; assim como a inexistência de uma constituição colonial unificada e de um estatuto único da população ultramarina. Se a heterogeneidade do estatuto político dos vassalos de além-mar criou uma pluralidade de tipos de laços políticos, a heterogeneidade de laços políticos impedia o estabelecimento de uma regra uniforme de governo, ao mesmo tempo em que criava limites ao poder da coroa ou dos seus delegados. Muitos de nós defendemos que, apesar da inequívoca centralidade do rei, ou da coroa, o império como um todo, os territórios e as populações ultramarinas caracterizavam-se pela falta de homogeneidade, por múltiplas centralidades e hierarquias sociais e políticas. Em relação aos novos estudos sobre o exercício da justiça régia nos domínios ultramarinos, a que me referi acima, afirmou-se entre nós, historiadores brasileiros - em diálogo, sobretudo, mas não só, com as obras de António Manuel Hespanha - o caráter pluralista do direito. Vários trabalhos demonstram que o pluralismo e a fluidez das normas e das leis na sociedade colonial poderiam significar um reflexo, e uma adaptação, da inconsistência jurídica da própria arquitetura do direito comum europeu no Antigo Regime, erguida sobre o princípio de que as regras particulares concorriam com as regras gerais. Essa característica do direito europeu resultou numa vantagem essencial quando os colonizadores tiveram de lidar 
com um mundo complexo e em constante movimento e mutação, como o dos territórios, domínios e sociedades ultramarinas. Por outro lado, cada vez mais e com maior argúcia estudos sobre os poderes locais, em especial, as câmaras municipais que, para além de instrumentos eficientes na organização política das vilas, cidade e elites coloniais - que as utilizaram para legitimar sua liderança política na defesa de seus interesses e no estabelecimento, ampliação e fortalecimento de suas redes sociais, como vem demonstrando recentes teses e dissertações defendidas no Brasil -, eram talvez, o mais eficaz contraponto do processo de centralização monárquica ou do absolutismo que porventura pudesse caracterizar o topo ou o centro da monarquia. Reitero que estas considerações sobre o estado atual da historiografia brasileira sobre o período colonial são feitas a partir da análise das recentes pesquisas que têm a ver com os meus próprios interesses e objetos de trabalho, uma vez que desde o meu doutorado venho me dedicando à política e à administração imperial.

OT - Há diálogo entre as produções dos diversos programas de pós-graduações espalhados pelo Brasil quando se trata de História do Brasil colonial?

Creio que sim. Tenho viajado para outros estados e universidades, para participar de congressos, seminários ou de bancas de defesa de teses e dissertações, e percebo uma produção bastante rica em temas e objetos, e bastante conectada com uma produção historiográfica de ponta, não só no Brasil, como também no exterior. Sou uma pesquisadora contumaz dos sites dos diferentes Programas de Pós-Graduação, não só para me atualizar em relação às novidades, mas para indicar trabalhos recém-defendidos a meus orientandos e alunos. Sei que há um interesse grande por parte dos alunos em relação às novas perspectivas historiográficas. É impressionante como, qualquer que seja o tema específico de uma comunicação, palestra ou conferência que eu apresente fora do Rio, a pergunta de muitos alunos é em relação aos argumentos defendidos pelos autores de $O$ Antigo Regime nos Trópicos e a crítica de Laura de Mello e Souza, publicada em $O$ Sol e a Sombra. No entanto, recentemente saiu, na revista Pesquisa, da FAPESP, uma matéria sobre o projeto "Dimensões do Império Português", desenvolvido na USP e coordenado por Laura, na qual os entrevistados - professores e pesquisadores que participaram da pesquisa - enunciam pontos de vista muito próximos aos por nós defendidos, desde 2001. De acordo com a matéria, o objetivo do projeto era rediscutir o conceito de antigo sistema colonial e ver se ainda tinha operacionalidade ante as novidades que a pesquisa histórica tem trazido. Segundo Laura de Mello e Souza, nessa releitura, o império português aparece como pouco homogêneo e com centros políticos relativamente autônomos. A seu ver, é preciso questionar a idéia de uma ideologia imperial unitária. Para ela, as colônias se constituíram também, mas não apenas, mimeticamente como espelhos, reproduzindo os valores socioculturais da península Ibérica. A matéria, no entanto, não tratou da influência ou mesmo do diálogo com outros historiadores, como os do Antigo Regime nos Trópicos; tampouco se referiu ao profícuo debate que vem sendo travado desde 2001, o que é uma pena e causou certa perplexidade. Mesmo assim, embora nosso arcabouço interpretativo da sociedade colonial e escravista a partir de práticas e da cultura política da monarquia portuguesa de Antigo Regime - e a intensa produção que se seguiu baseada na mesma interpretação - não tenham sido mencionados, qualquer um de nós que leia a matéria, poderá perceber 
que, por meio de pesquisas acuradas e da produção nos mais diversos Programas de Pós-Graduação em nosso país, inclusive na USP, os argumentos por nós defendidos são de extrema pertinência e atualidade, o que demonstra, mais uma vez, a importância dessa obra como difusora de um novo paradigma de interpretação da história colonial do Brasil, que agora parece ser amplamente partilhado.

OT - Qual o papel da historiografia portuguesa nas atuais pesquisas sobre Brasil colonial?

Sempre houve diálogo entre as historiografias no Brasil e em Portugal. Lembrome que, quando comecei a ministrar disciplinas sobre o período colonial, ainda na década de 1980, entre as obras fundamentais para a compreensão da expansão portuguesa e das dinâmicas do império, destacavam-se os estudos de Vitorino Magalhães Godinho. No entanto, creio que nunca, como hoje, essa aproximação e diálogo foram tão ricos e sistemáticos. Diria mesmo que se a historiografia portuguesa desempenhou e vem desempenhando importante papel na renovação das pesquisas e análises sobre o Brasil colonial, da mesma forma, nossa historiografia e nossa vastíssima produção têm influenciado, de maneira inequívoca, os trabalhos de historiadores portugueses que se dedicam ao Antigo Regime europeu. Não é mais possível, hoje, pensar a monarquia portuguesa nos tempos modernos, sem se levar em conta as configurações e as dinâmicas de seu império ultramarino. Portanto, esse diálogo e essa "influência" são uma via de mão-dupla. Basta pensarmos nas inúmeras publicações, tanto no Brasil, quanto em Portugal, que contam com a participação de historiadores dos dois lados do Atlântico. Cito aqui a análise extremamente lúcida de Maria de Fátima Silva Gouvêa num dos últimos artigos que escreveu. Para ela, as conseqüências desse trabalho em conjunto "foram tremendas", no que diz respeito à forma como vinham até então sendo compreendidas as interseções entre o processo de formação dos Estados modernos e o de constituição dos impérios ultramarinos. Fátima defendia que a formação do império português resultava de uma curiosa engenharia político-econômica que, desde o século $\mathrm{XV}$, combinava de modo dinâmico $\mathrm{o}$ recrutamento e a remuneração de indivíduos na prestação de serviços que viabilizaram a incorporação das novas conquistas à soberania portuguesa. Para ela - com o que concordamos - é impossível dissociar o processo de formação do Estado, em Portugal, de seu império ultramarino, ambos fundados no binômio relacional gerado pela prestação de serviços à coroa. Exímia historiadora que era, entendia a monarquia e o império como dimensões de um mesmo processo formativo e expansionista, no qual a centralidade da coroa operava como elemento decisivo na conformação e no reconhecimento dos poderes e das hierarquias sociais instituídas. Caberia concluir que o diálogo entre as duas historiografias - no Brasil e em Portugal - promoveu um profundo deslocamento na forma de se perceber a dinâmica das relações de poder na época moderna. Se por um lado, apesar da pluricontinentalidade da monarquia portuguesa para usar um conceito de Nuno Gonçalo Monteiro - é impossível desconsiderar a centralidade da coroa nesse feixe de relações, por outro, não podemos deixar de levar em conta a centralidade do ultramar na formação da sociedade e da economia portuguesa na época moderna. E estas conclusões foram em grande medida possíveis devido ao intenso e profícuo diálogo travado nos últimos anos entre historiadores portugueses e brasileiros. 